\title{
Ética y economía. La relación marginada
}

\author{
Kliksberg, Bernardo*
}

\section{Resumen}

Se podría preguntar: habiendo tantos problemas importantes concretos para la población tiene sentido hablar de valores, de ética?, Es ese un tema postergable, no urgente? Pensamos que la pregunta debería invertirse. Cómo pueden diseñarse políticas económicas, asignarse recursos, determinarse prioridades, sin discutir los aspectos éticos, la moralidad de lo que se está haciendo a la luz de los valores que deberían ser el norte del desarrollo y la democracia. En América Latina esa discusión ha sido postergada. Es hora de retomarla porque puede arrojar muchas luces en una época de fuertes confusiones. Se enfocan en primer término algunos problemas de la región que son económicos y sociales, pero al mismo tiempo profundamente éticos, en segundo lugar, se cuestionan ciertas "coartadas" comunes frente a ellos. Por último, se mencionan valores éticos que tendrían que orientar la selección de políticas y la acción por el desarrollo.

Palabras clave: Ética, marginalidad, economía, valores.

\section{Ethics and Economy. The Marginalized Relation}

\section{Abstract}

One could ask: with so many concrete and important problems in society, is it sensible to talk about ethics? Is this theme deferrable; not urgent? We feel that the question should be inverted. How can we design economic policy, assign resources, and determine priorities without discussing ethical aspects, and the morality of what is being done in reference to the values that should orient development and democracy? In Latin America this discussion has been postponed. It is time to look

\section{Recibido: 01-09-22 . Aceptado: 01-11-07}

* Director de la Iniciativa Interamericana de capital social, Ética y Desarrollo del BID. Ex Director del Proyecto de las Naciones Unidas para América Latina de Modernización del Estado y $\mathrm{Ge}-$ rencia Social. Profesor Honorario de la Universidad Nacional de Buenos Aires. Autor de numerosas obras. Entre las últimas: Capital social y cultura. Claves estratégicas para el desarrollo (Fondo de Cultura Económica). El nuevo debate sobre el nuevo desarrollo y el rol del Estado (Instituto Nacional de Administración Pública de México). Pobreza. Un tema impostergable Nuevas respuestas a nivel mundial (Fondo de Cultura Económica). Social Management: some strategic issues (United Nations, New York). El Rediseño del Estado, Una perspectiva internacional (Fondo de Cultura Económica). 
at it again because it could throw light on the subject in this moment of confusion. Certain economic and social problems of this region are focused on first, which are profoundly ethical. In the second place, certain common "excuses" used in reference to them are questioned. Finally, certain ethical values are mentioned that could orient the selection of development policies and actions.

Key words: Ethics, marginality, economics, values.

\section{Desafíos a la ética}

La civilización occidental tiene firmes convicciones en materia de valores que permean la cultura, y que la población espera dirijan la vida pública, y el comportamiento individual. Ciertos desarrollos en la región las violan a diario. Identificaremos algunos de una lista que puede ser mucho más amplia.

- Según nuestra moral, los niños deberían gozar de todas las oportunidades para su desenvolvimiento. La protección de su salud, y su educación son prioridades indiscutidas en Occidente. En América Latina según los datos recientes 6 de cada 10 niños menores de cinco años de edad son pobres. La pobreza implica negaciones concretas de los derechos básicos de los niños a lo más elemental. Millones de niños menores de 14 años de edad trabajan, aumenta a diario un cuadro extremo que contraria todos los valores éticos, el número de niños que viven en las calles de las grandes urbes abandonados por la sociedad se incrementa de igual modo la utilización de los niños en los circuitos de la drogadicción y la prostitución.

- Nuestra civilización tiene como fundamento básico la institución familiar. Es la unidad pilar del tejido social. Deberían estar abiertas de par en par las posibilidades para formar familias, y para que ellas puedan desarrollarse. En los hechos, sé esta produciendo una seria erosión de la unidad familiar, ante las tensiones fenomenales que genera en ella la pobreza que afecta a amplios sectores de la población. El problema no sólo se da en los estratos populares sino afecta también fuertemente a los "nuevos pobres", las clases medias en descenso. Las cifras dicen que aumenta el número de madres pobres que han quedado solas al frente del hogar, que se ha incrementado el indicador de renuencia a formar familias de los jóvenes ante las incertidumbres que implica poder sostenerlas, que aumentan los niños extramatrimoniales, que está subiendo un índice alarmante, violencia doméstica.

- La desocupación es un grave problema económico y social. Pero al mismo tiempo no puede dejar de verse que es una cuestión ética. No sólo implica no percibir una remuneración, causa daños muy graves a las personas en aspectos vitales. Así el Nobel de Economía Robert Solow (1995), señala que la economía convencional se equivoca cuando dice que es un tema de oferta y demanda. Dicha economía supone que los desocupados por períodos prolongados van a buscar activamente trabajo, van a bajar sus pretensiones salariales, y se alcanzara un nuevo equilibrio en el que encontraran trabajo. Solow muestra que cuando una persona esta desocupada por un buen tiempo, sufre todo orden de daños psicológicos. Es 
vulnerada su autoestima, su familia se tensa al máximo, se siente excluido de la sociedad. Según las investigaciones, en lugar de buscar intensamente trabajo tiende a retirarse del mercado laboral por temor a sufrir nuevos rechazos, y asimismo tiende a retraerse socialmente por la "vergüenza" de no tener trabajo. Son sufrimientos que afectan la dignidad humana. En América Latina la tasa de desocupación es elevada, el $8 \%$, y la de los jóvenes duplica la tasa promedio.

La civilización judeo-cristiana considera que todos los seres humanos son iguales, criaturas de la divinidad, que merecen el pleno acceso a oportunidades de desarrollarse. Las desigualdades agudas vulneran ese credo igualitario, y han sido condenadas tanto en el Antiguo como el Nuevo Testamento. América Latina presenta agudas polarizaciones sociales. Constituyen según han demostrado numerosas investigaciones una traba fundamental para el desarrollo, pero al mismo tiempo contradicen el credo de la igualdad de oportunidades. Entre ellas: el 10\% más rico de la población tiene un ingreso que es 84 veces el del $10 \%$ más pobre (es la mayor brecha social del planeta). Hay desigualdad en el acceso al crédito. Las pequeñas y medianas empresas, sólo tienen el $5 \%$ del crédito del sistema financiero. Hay desigualdad en el acceso a factores básicos en materia de salud, como agua potable (los pobres carecen de ella, y la pagan mucho más caro), sistemas de at cantarillado, electricidad, y protección medica básica. A pesar de los avances, las brechas de esperanza de vida, mortalidad infantil, y mortalidad materna, entre estratos sociales son muy fuertes. Hay grandes inequidades en cuanto a la posibilidad de completar educación primaria y secundaria, y en cuanto a la calidad de la educación recibida.. Hay una nueva brecha, las desigualdades pronunciadas en el acceso a la tecnología de punta, la informática. Menos del $1 \%$ de la población tiene acceso a Internet.

\section{Las falsas coartadas}

Frente a estos y otros problemas que son una afrenta a los valores éticos de nuestra civilización, suelen circular ciertos razonamientos que pueden considerarse "coartadas" destinadas a atenuar o marginar, los conflictos éticos existentes.

- Se trata de convertir la pobreza en un problema individual. Los pobres lo serían porque no han hecho suficientes esfuerzos en su vida, o tienen tendencias hacia el alcoholismo, la indolencia, etc. Señala categóricamente un difundido informe de una Comisión de personalidades presidida por Patricio Aylwin (1995), que ello no tiene ninguna sustentación. Cuando una de cada dos personas es pobre, evidentemente hay problemas del contexto que están creando esa situación. Por otra parte, destaca que es bien claro que cuando las políticas aplicadas abren oportunidades reales a los pobres, las aprovechan a fondo como cualquier otro sector de la población.

- Se plantea que las desigualdades son inevitables, son una especie de ley de la naturaleza. Formarían parte del proceso de modernización de una sociedad. Un prominente economista Atkinsons (1998), dice que claramente están influidas por factores como las políticas públicas implementadas, y las actitudes culturales prevalecientes frente a la inequidad. 
Cuando ambas son proequidad, la situación cambia. Ello explica los buenos niveles de equidad obtenidos en países como entre otros Suecia, Noruega, Dinamarca, Japón, Canadá, Holanda.

- Se plantea que la solidaridad es una especie de anacronismo, un valor premoderno. Que debe darse el máximo énfasis al individualismo, y que cada uno debe hacerse responsable por sí mismo. Los textos bíblicos proclaman lo contrario. La orientación a la solidaridad forma parte central de la calidad humana, y ennoblece a las personas.. Por otra parte, muchos de los países líderes del mundo actualmente en economía y tecnología, tienen sociedades civiles con altos grados de ejercicio de la solidaridad, con multiplicidad de organizaciones no gubernamentales de acción solidaria, y ejércitos de trabajadores voluntarios.

- Se dice que el fin justifica los medios. Que los sufrimientos sociales infligidos son para obtener fines superiores. Ciertamente ese era el pensamiento de Maquiavelo. Pero los textos bíblicos dicen lo contrario. Proclaman que "el fin no santifica los medios". Albert Einstein reflexionaba al respecto "Quien puede dudar que Moisés (que entregó los Diez Mandamientos) fue mejor conductor de hombres que Maquiavelo".

\section{Recuperar la ética}

Uno de los mayores filósofos de nuestro tiempo Taylor (1995), lanza en "The Ethics of Autenticity" (Harvard University Press), una advertencia sugerente. Señala que nuestra época se caracteriza porque la discusión se ha concentra- do sobre los medios, como la economía y la tecnología, y siendo ello muy relevante, no se puede olvidar que son medios al servicio de fines últimos. Sobre estos no se discute, y aun más previene el filósofo, la discusión sobre los medios tiende a eliminar y sustituir la que debería llevarse a cabo sobre los fines.

Esta última es el terreno de la ética. Corresponde volver a plantearse: a dónde vamos?, Qué tipo de sociedad queremos?, Qué valores son irrenunciables?, Qué valores deberían ser un marco de referencia obligado en el diseño de políticas publicas?, Y otras preguntas semejantes.

Enfrentar los problemas éticos, y abrir el debate eludido por las falsas coartadas, llevará probablemente al rescate entre otros, como valores que deberían orientar los esfuerzos por el desarrollo, de los siguientes:

- La pobreza es intolerable. La voz profética señala en la Biblia "No habrá pobres entre vosotros". Como resalta un prominente filósofo Leibowitz (1999), no está diciendo lo que va a suceder, sino lo que debería suceder. Que haya o no pobreza depende de las sociedades organizadas.

- Somos todos responsables los unos por los otros. La insolidaridad es contraria a la dignidad humana. "Ama a tu prójimo como a ti mismo"proclamaba Jesús de Nazareth.

- Es necesario superar todas las formas de discriminación activamente subsistentes aun en la región, como las que ejercen contra las mujeres, los indígenas, los grupos afroamericanos, los discapacitados, las edades mayores, y otras.. Corresponde a todos los seres humanos el pleno respeto, y los mismos derechos. 
- Hay muchas maneras de ayudar al prójimo. Maimónides las clasifico, teniendo en cuenta la genuinidad de la voluntad de ayudar, el grado de anonimato, el respeto por el otro, y la utilidad final de la ayuda. El grado inferior de los ocho niveles de su tabla, es aquel que ayuda de mala gana, forzado por otros. El superior es quien ayuda de tal modo que el otro no necesite después mas ayuda. Esa debería ser la meta.

- En investigaciones recientes los pobres reclaman que lo que más les duele de la pobreza es que sienten que son menospreciados a diario en su condición humana, incluso por algunas de las organizaciones que intentan ayudarlos (The world Bank, 2000). Las señales explícitas o implícitas que reciben son de subestimación, menosprecio, consideración como personas de segunda categorías, como seres in feriores. Se necesita una solidaridad, que respete profundamente la cultura de los pobres, sus valores, que abra espacios al fortalecimiento de sus propias organizaciones, y al crecimiento de su autoestima.

- La pobreza debe considerarse como un tema de derechos humanos violados. Ataca los derechos más elementales de las personas. Así lo ha proclamado recientemente las Naciones Unidas.

- La constitución de sociedades democráticas estables, y activas, requiere de la construcción de ciudadanía. Uno de sus componentes centrales es la restitu ción de los derechos a oportunidades productivas y de desarrollo que son negados por la pobreza.

Será ilusorio pretender que valores como estos puedan influir en las políticas? En primer lugar están en la esencia de la identidad humana. Por otra parte parece haber un extendido clamor en las democracias para que sean tenidos en cuenta. Respondiendo a el se ha comenzado a hacer interrogaciones éticas y buscar soluciones para ellas en temas económicos claves.

Esa conciencia en aumento está llevando a la organización de "frentes éticos" que han conducido amplias movilizaciones y han conseguido resultados concretos. Veamos algunos casos recientes.

- Existen en el mundo 36 millones de personas con SIDA. El $70 \%$ viven en África. En el año 2000 cerca de 3 millones de personas murieron por la enfermedad, y más de 5 millones contrajeron el virus, el $80 \%$ africanos. $\mathrm{Si}$ no se toman medidas de fondo, países como Sudáfrica, Zimbawe, y Zambia verán devastada su población y sufrirán decenas de millones de muertes en los próximos años. 5000 africanos mueren diariamente por el mal. Existen nuevas drogas para atacarlo, pero sus precios de venta las colocan fuera de alcance. Los africanos no pueden pagar 10.000 dólares anuales por el llamado triple compuesto antisida. Laboratorios hindúes y brasileños han demostrado que se puede producir como genérico por menos de 500 dólares. Diversos laboratorios internacionales demandaron al Gobierno de Sudáfrica por intentar generarlo. Un gran movimiento de opinión pública presionó en nombre del principio ético básico: el derecho a la vida. Los laboratorios se vieron obligados a retirar sus demandas. 
- Siete millones de personas mueren anualmente por enfermedades prevenibles o curables como la tuberculosis y la malaria. Son pobres en su gran mayoría, no son "mercado". Los grandes laboratorios no tienen por ende interés en estos temas. El último fármaco contra la tuberculosis que salió al mercado fue elaborado en 1967. Según informa la American Medical Association, de los 1223 nuevos fármacos que salieron al mercado entre 1975 y 1997 solo 13 eran para el tratamiento de enfermedades tropicales. El reclamo ético ha llevado a que se esté por constituir un Fondo Mundial publico para buscar soluciones masivas al SIDA y éstas enfermedades.

- Crece el movimiento ético por reglas de juego económicas diferentes. La exigencia mundial encabezada por el Papa Juan Pablo II para la reducción de la deuda externa de los países pobres ha llevado a que se alteraran principios del sistema financiero internacional que eran considerados inamovibles. Otro fuerte frente de protesta ética, está cuestionando las barreras proteccionistas que ponen muchos países desarrollados a las exportaciones básicas de los países pobres. Las tarifas aduaneras son discriminatorias, escalan cuando hay valor agregado de procesamiento en los productos de los países en desarrollo, y los subsidios a la agricultura de los países ricos son muy elevados. Afirma el economista jefe del Banco Mundial Nicholas Stern: "La clase de proteccionismo practicada por las naciones industrializadas más ricas es simplemente indefendible. El costo de los países en desarrollo en oportunidades de exportación perdidas es mucho mayor a la ayuda para el desarrollo que reciben" (Drozdick, 2001) El Secretario General de la ONU Koffi Annan (2001) ha planteado dirigiéndose a los países desarrollados: "Los países pobres no quieren vuestra caridad, simplemente quieren el derecho a vender sus productos en vuestro mercados a precios correctos". Acusando la protesta La Unión Europea tomo hace poco la decisión de abrir sus mercados para los productos de los 48 países más pobres del mundo.

- En diversos países desarrollados, surgen protestas éticas frente a la aplicación de ciertas ortodoxias económicas. Así en USA una solicitud firmada por 200 prominentes empresarios expresó su oposición al proyecto de eliminar el impuesto a la herencia. Alegaron que eso solo beneficiaría al $2 \%$ más rico de la población, llevaría a reducciones en los presupuestos públicos sociales, y que las ONGS sociales dejarían de recibir casi 6.000 millones de dólares anuales de donaciones (New York Times, 2001). Otra solicitud denunció la existencia en USA de 43 millones de personas sin ningún seguro médico, y señaló que las organizaciones empresariales, sindicales, ONGS, firmantes "pensamos que el derecho de acceso a una cobertura de salud viable de buena calidad para todos debe ser una prioridad nacional".

- Crece el frente mundial ético de protesta por las extremas desigualdades 
de nuestro tiempo, y el simultaneo descenso de la ayuda internacional para el desarrollo. Habiendo aproba do los países desarrollados que debían dedicar el $0.7 \%$ del PBI a dicha ayuda, solo cuatro países cumplen con ello: Noruega, Suecia, Dinamarca y Holanda. Los países desarrollados aportan en promedio solo el $0.24 \%$, y USA el $0,1 \%$.

Son inicios, pero estimulantes. EI tiempo sin embargo es corto, particularmente en América Latina. Aquí debería sumarse a los otros valores, la noción de que debe haber una "ética de la prisa". Cada día que transcurre sin respuestas adecuadas a los sufrimientos de la población significa daños en muchos casos irreversibles. Niños que por la desnutrición experimentaran daños para toda la vida, familias que serán destruidas sin que después ello sea enmendable, jóvenes que la desocupación permanente incentivara a la delincuencia, vidas perdidas o mutiladas. Como lo resaltara Juan Pablo II (1999) "La pobreza es algo urgente, que no puede esperar".

\section{Bibliografía Citada}

Atkinson, A.B. (1998). Equity issues in a globalizing world: the experience of OECD countries. Conference on Economic Policy and Equity. IMF. June 8-9.

Aylwin, Patricio y otros (1995). Informe de la Comisión Latinoamericana y del Caribe sobre el desarrollo social. BID, CEPAL, PNUD.

Drozdick, W. (2001) "Poor Nations may not buy trade talks". Washinton Post Foreign Service, 15 de Mayo.

Juan Pablo II (1999). Discurso en Elk, Polonia, 8 de Junio.

Kofi Annan (2001). Apertura de la Conferencia Internacional sobre países más pobres, Bruselas, 14 de Mayo.

Yeshahahu Leibowitz (1999). Breves reflexiones bíblicas. Edición en español, AIV, Venezuela.

Responsible wealth. If tre estate tax is eliminated someone else will pay. The Neww York Times, February 182001.

Solow, Robert (1995). Mass unemployment as a social problem. En Bassu, Pattanaik y Suzumura. Choice, welfare and development. Clarendon Press, Oxford.

Taylor, Charles (1995). The ethics of Autenticity. Harvard University Press.

The World Bank (2000). The voices of the poor. Washington. 